\title{
Pengenalan dan Deteksi Dini Stunting Dalam Tumbuh Kembang Anak di Panti Asuhan Nurul Akbar
}

\author{
Rezky Putri Indarwati Abdullah ${ }^{1}$, Muhammad Wirasto Ismail ${ }^{2}$, Inna Mutmainnah ${ }^{3}$ \\ ${ }^{1}$ Departemen Ilmu Kesehatan Masyarakat, Fakultas Kedokteran, Universitas Muslim Indonesia, \\ Makassar, Indonesia \\ ${ }^{2}$ Departemen Hukum, Fakultas Kedokteran, Universitas Muslim Indonesia, Makassar, \\ Indonesia \\ ${ }^{3}$ Departemen Ilmu Gizi, Fakultas Kedokteran, Universitas Muslim Indonesia, Makassar, \\ Indonesia
}

*Email Korespondensi: rezkyputri.abdullah@umi.ac.id

Telp: +62-85242632368

\begin{abstract}
ABSTRAK
Masalah stunting menggambarkan masalah gizi kronis, yang dipengaruhi oleh kondisi ibu atau ibu hamil, masa janin, dan bayi atau balita, termasuk penyakit yang diderita selama masa kanak-kanak. Metode : Memberikan penyuluhan mengenai stunting pada anak dengan menggunakan alat bantu seperti flipchart, dan food model sehingga lebih mudah dimengerti kemudian melakukan pemeriksaan tinggi badan dan berat badan anak. Hasil : didapatkan bahwa tidak ada satupun orang tua yang mengetahui apa yang dimaksud dengan stunting. Dari data hasil pemeriksaan tinggi badan terhadap usia pada anak panti didapatkan dari 38 peserta yang dilakukan pengukuran tinggi badan menurut umur, terdapat 8 orang anak yang berusia $0-5$ tahun dan 3 orang diantaranya menderita stunting dengan persentase $37,5 \%$. Tujuan : Menambah pengetahuan masyarakat tentang deteksi dini dan pencegahan terjadinya stunting pada anak serta memberikan analisa dan hasil pemeriksaan berat badan, tinggi badan serta status gizi anak lainnya sebagai deteksi dini terhadap terjadinya stunting pada anak. di Panti Asuhan Nurul Akbar. Kesimpulan : Pengetahuan masyarakat bertambah dari tidak tahu sama sekali menjadi tahu dan pada analisa dan hasil pemeriksaan tinggi badan dan usia pada anak panti didapatkan dari 38 peserta, terdapat 8 orang anak yang berusia $0-5$ tahun dan 3 orang diantaranya menderita stunting dengan persentase $37,5 \%$
\end{abstract}

Kata kunci: Pengenalan; pencegahan; deteksi dini; stunting.

\begin{abstract}
The problem of stunting describes chronic nutritional problems, which are influenced by the condition of the mother or pregnant woman, the fetus, and the baby or toddler, including illnesses suffered during childhood.

Methods: Providing education about stunting to children using assistive devices such as flipcharts and a food model so that it is easier to understand and then checking the child's height and weight. Objective: Increase public knowledge about early detection and prevention of stunting in children and provide analysis and results of examinations on weight, height and nutritional status of other children as early detection of stunting in children. at the Nurul Akbar Orphanage. Result: it is found that none of the parents know what is meant by stunting. From the data on the results of examining height for age in orphanage children, it was obtained from 38 participants who measured their height according to age, there were 8 children aged 0-5 years and 3 of them was stunting (37.5\%). Conclusion: Public knowledge increases from not knowing at all to knowing and the analysis and results of the examination of the height and age of the orphanage children were obtained from 38 participants, there were 8 children aged 0-5 years and 3 of them suffered from stunting with 37, 5\%
\end{abstract}

Keywords: Recognition, prevention, early diagnosis; stunting 


\section{PENDAHULUAN}

Usia balita merupakan periode emas dalam menentukan kualitas sumber daya manusia yang dilihat dari segi pertumbuhan fisik maupun kecerdasan, sehingga hal ini harus didukung oleh status gizi yang baik.(1) Asupan gizi sangat diperlukan pada masa ini, karena dapat mempengaruhi pertumbuhan dan perkembangan. Hal ini akan memberi dampak sangat luas yang berefek pada masa depan anak.(2)

Permasalahan gizi pada balita yang hingga saat ini masih cukup besar dan belum terselesaikan adalah stunting, yang merupakan salah satu menifestasi utama dari malnutrisi, hasil sebuah proses patologis yang berhubungan dengan kegagalan untuk mencapai pertumbuhan linier potensial atau gagal mencapai tinggi badan relatif terhadap umur. Anak dikatakan stunting jika memiliki panjang/tinggi badan menurut umur dibawah -2 SD median standar pertumbuhan anak.(3)(4)

Stunting tidak hanya menjadi permasalahan gizi balita secara nasional, melainkan sudah menjadi permasalahan global.(3) Berdasarkan publikasi terbaru WHO menunjukkan bahwa jumlah stunting secara global mencapai 154,8 juta balita.(5) Data prevalensi anak balita stunting yang dikumpulkan World Health Organization (WHO) yang dirilis tahun 2018 menyebutkan Indonesia termasuk ke dalam negara ketiga dengan prevalensi tertinggi di SouthEast Asian Region setelah Timor Leste (50,5\%) dan India (38,4\%) yaitu sebesar 36,4\%.(6)

Anak yang terkena stunting hingga usia 5 tahun akan sulit untuk diperbaiki sehingga akan berlanjut hingga dewasa dan dapat meningkatkan risiko keturunan dengan berat badan lahir yang rendah (BBLR).(7) Menurut Aryastami (2017) Berat badan lahir merupakan indikator penting dan dapat diandalkan untuk menentukan status kesehatan, gizi dan sosial ekonomi masyarakat di negara maju dan berkembang.(8) Menurut penelitian Nasution (2015), anak dengan riwayat BBLR memiliki risiko lebih besar untuk mengalami stunting dibandingkan anak yang lahir dengan berat normal.(9) Peranan keluarga terutama ibu dalam mengasuh anak sangat menentukan status gizi dan kualitas tumbuh kembang anak. Pola pengasuhan secara tidak langsung akan mempengaruhi status gizi anak. Untuk menunjang asupan gizi yang baik perlu didukung oleh kemampuan ibu dalam memberikan pengasuhan yang baik kepada anak dalam praktik pemberian makan, praktik kebersihan diri dan lingkungan. Menurut United Nations Children's Fund (UNICEF) pola asuh merupakan salah satu faktor tidak langsung yang berkaitan dengan status gizi anak termasuk stunting.(10)

Sulawesi Selatan merupakan provinsi dengan urutan ke-3 yang masuk dalam kategori serius setelah Papua dan Maluku. Prevalensi stunting di Provinsi Sulawesi Selatan sebesar 
$38,9 \%$ (sangat pendek $15,8 \%$ dan pendek $23,1 \%$ ). Prevalensi tertinggi stunting berdasarkan kelompok umur terdapat pada kelompok usia 12-35 bulan.(11) Berdasarkan data Pemantauan Status Gizi (PSG) Sulawesi Selatan tahun 2015 yang dilakukan di 24 kabupaten/kota menunjukkan bahwa prevalensi balita stunting pada tahun 2014 sebesar 34,5\%. Mengalami penurunan pada tahun 2015 menjadi 34,1\%. Angka ini menunjukkan bahwa posisi Sulawesi Selatan di tahun 2015 masih belum mencapai target MDGs yaitu 32\%. Salah satu dari kabupaten tersebut yang memiliki prevalensi stunting yang cukup tinggi yaitu Kabupaten Enrekang yang menduduki urutan ke-6 dengan prevalensi stunting sebesar 39,6\%.(12)

Dari pendahuluan diatas, kegiatan ini bertujuan untuk :

- Menambah pengetahuan dan pemahaman masyarakat tentang deteksi dini dan pencegahan terjadinya stunting pada anak di Panti Asuhan Nurul Akbar

- Memberikan analisa dan hasil pemeriksaan berat badan, tinggi badan serta status gizi anak lainnya sebagai deteksi dini terhadap terjadinya stunting pada anak.

\section{METODE PELAKSANAAN}

\subsection{Solusi dan Target Luaran (contoh)}

Penyuluhan terkait perngenalan dan pencegahan terjadinya stunting pada anak serta deteksi dini stunting diharapkan mampu memberikan pemahaman kepada masyarakat luas tentang apa itu stunting dan efek jangka panjang yang dapat terjadi sehingga deteksi dini dilakukan guna dapat mengejar atau mencapai tinggi badan yang optimal sebelum berusia 5 tahun. Adapun target yang telah didapat dari hasil Tanya jawab tentang stunting, bahwa tidak ada yang mengetahui apa itu stunting dan setelah penyuluhan, 50\% diantara sudah mengetahui.

\subsection{Lokasi Kegiatan Pelaksanaan (contoh)}

Waktu Pelaksanaan bulan Agustus 2020 di Panti Asuhan Nurul Akbar Makassar.

\subsection{Metode Kegiatan}

2.3.1 Melakukan koordinasi dengan Kepala Panti Asuhan Nurul Akbar.

2.3.2 Mengetahui dan mendata jumlah peserta yang akan ikut berpartisipasi dalam kegiatan ini.

2.3.3 Mendata tingkat pengetahuan peserta mengenai stunting pada anak.

2.3.4 Melakukan penyuluhan mengenai stunting pada anak dengan menggunakan alat bantu seperti flipchart dan food models sehingga lebih mudah dimengerti. 
2.3.5 Melakukan pemeriksaan tinggi badan sebagai langkah awal untuk deteksi dini stunting pada anak.

2.3.6 Melakukan pemeriksaan berat badan, tinggi badan untuk mendeteksi status gizi dan pertumbuhan anak.

2.3.7 Menginterpretasikan hasil pemeriksaan

2.3.8 Menjelaskan hasil pemeriksaan.

2.3.9 Melakukan evaluasi untuk mengetahui keberhasilan dari kegiatan ini.

2.3.10 Membentuk seorang kader dalam ruang lingkup Panti Asuhan Nurul Akbar

\section{HASIL DAN PEMBAHASAN}

Berdasarkan dari hasil tanya jawab kepada seluruh peserta pengabdian masyarakat ternyata tidak ada yang mengetahui tentang apa itu stunting atau gejala-gejala dari stunting, didapatkan bahwa tidak ada satupun orang tua yang mengetahui apa yang dimaksud dengan stunting. Dari data hasil pemeriksaan tinggi badan terhadap usia pada anak panti didapatkan dari 38 peserta yang dilakukan pengukuran tinggi badan menurut umur, terdapat 8 orang anak yang berusia 0-5 tahun dan 3 orang diantaranya menderita stunting dengan persentase 37,5\%. Angka ini merupakan angka yang cukup tinggi jika diinterpretasikan dengan anjuran WHO yakni angka stunting di suatu negara hanya $20 \%$ sehingga dibentuknya kader stunting agar dapat mencegah terjadinya kasus berulang dan anak yang sudah menderita stunting dalam usia yang belum 5 tahun dapat mengejar ketertinggalan untuk mencegah komplikasi jangka panjang yang bisa terjadi.

\section{GAMBAR, ILUSTRASI DAN FOTO}
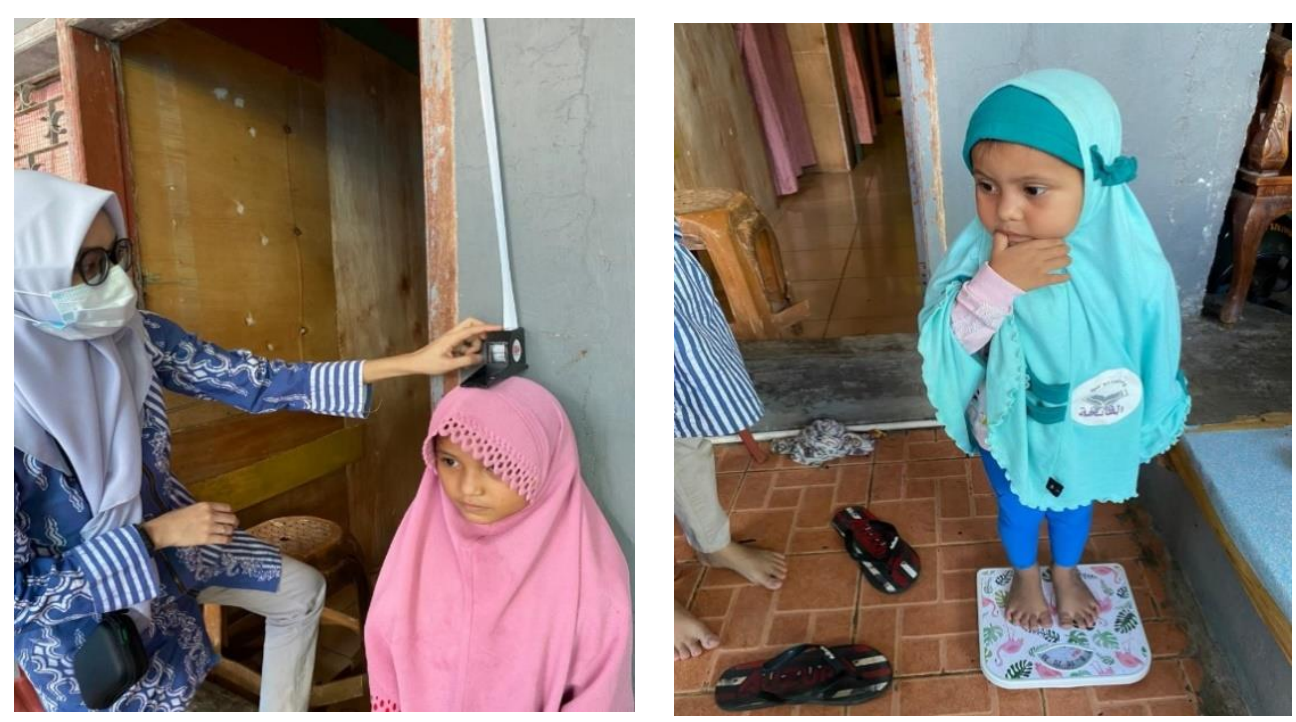

Gambar 1. Pemeriksaan Antropometri untuk deteksi dini stunting 


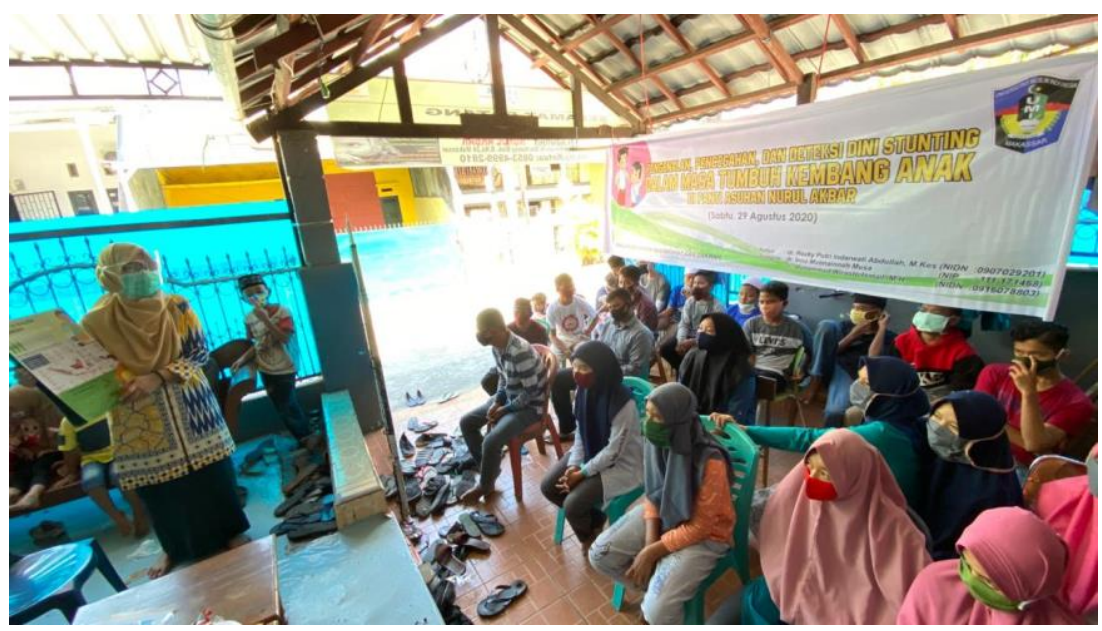

Gambar 2. Penyuluhan terkait stunting dengan media flip chart dengan menerapkan konsep protokol kesehatan

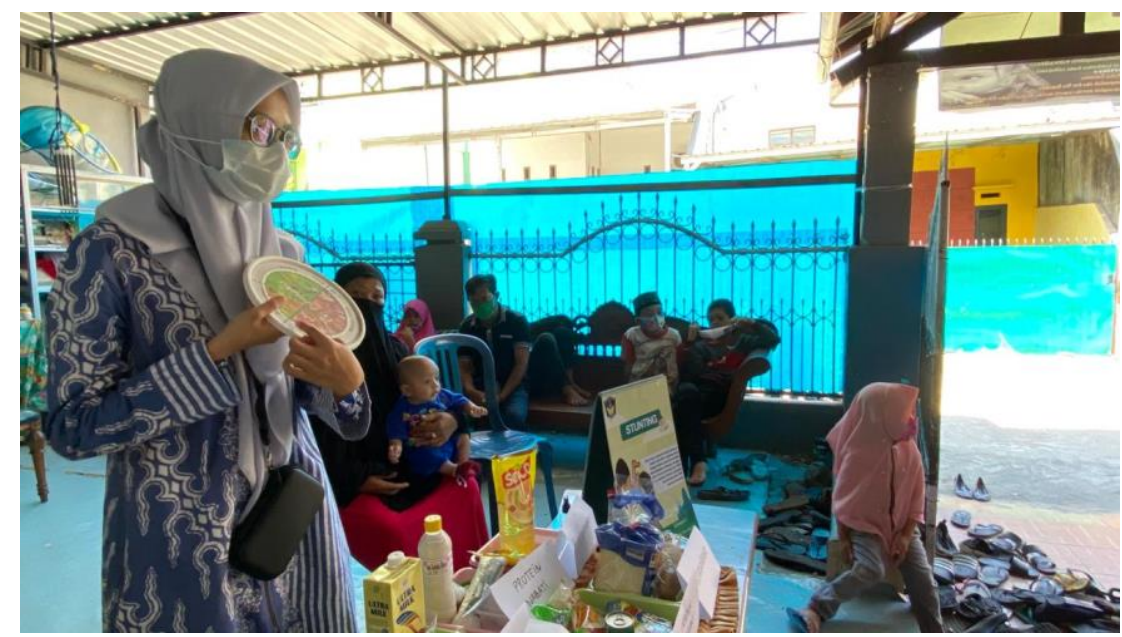

Gambar 3. Penyuluhan terkait stunting dengan media food model dengan menerapkan konsep protokol kesehatan

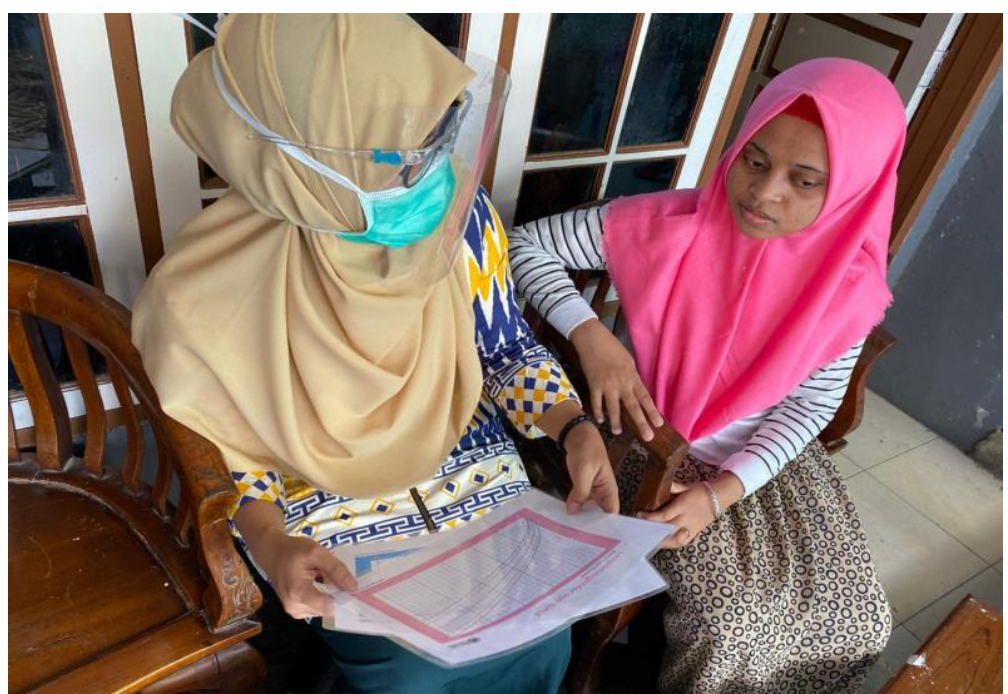

Gambar 4. Membentuk kader untuk deteksi dini stunting di wilayah Panti Asuhan Nurul Akbar 


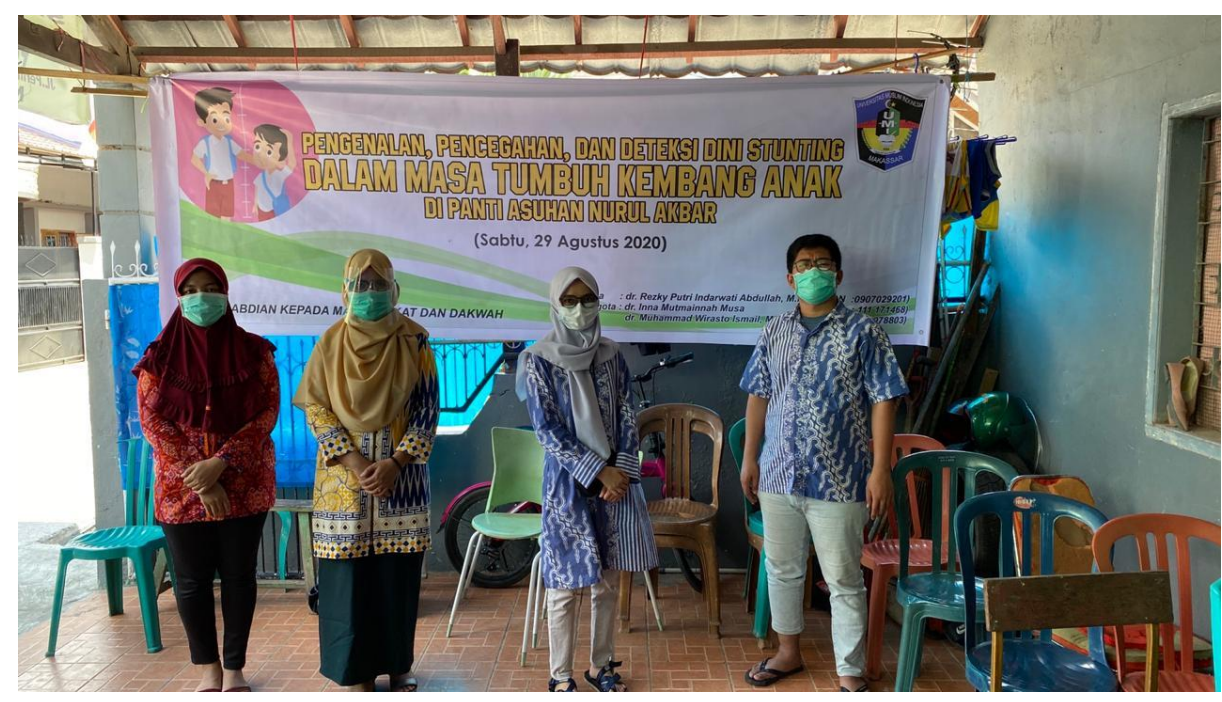

Gambar 5.Tim Pelaksana Pengabdian Masyarakat

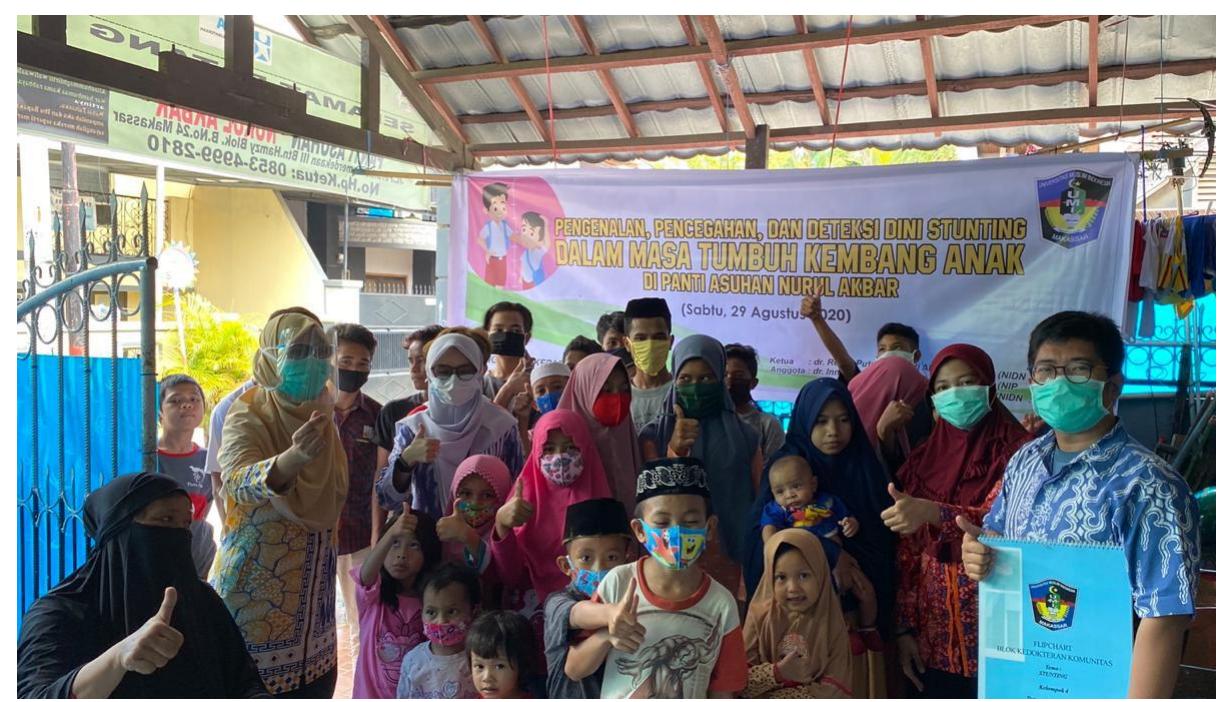

Gambar 6. Foto Bersama seluruh anak panti dan masyarakat umum sekitar Panti Asuhan Nurul Akbar

Tabel 4.1. Hasil Pemeriksaan Antropometri menurut TB/U

\begin{tabular}{clccc}
\hline No. & Nama & Usia (tahun) & Tinggi Badan $(\mathbf{c m})$ & Keterangan \\
\hline 1 & Nining & 17 & 153 \\
\hline 2 & Ning & 13 & 152 \\
\hline 3 & Putri & 12 & 150 \\
\hline 4 & Nawar & 13 & 159 \\
\hline 5 & Karmila & 19 & 152,5 \\
\hline 6 & Ina & 16 & 150,5 \\
\hline 7 & Nurmi & 17 & 152 \\
\hline 8 & Hanafia & 16 & 149 \\
\hline 9 & Astri & 15 & 151 \\
\hline 10 & Arifin & 19 & 162 \\
\hline
\end{tabular}




\begin{tabular}{|c|c|c|c|}
\hline 11 & Abdullah & 15 & 156,5 \\
\hline 12 & Tan & 15 & 159 \\
\hline 13 & Supar & 15 & 154 \\
\hline 14 & Ferdi & 15 & 152 \\
\hline 15 & Angga & 13 & 144 \\
\hline 16 & Ferry & 20 & 160 \\
\hline 17 & Wahyu & 18 & 166 \\
\hline 18 & Zainuddin & 18 & 161,5 \\
\hline 19 & Taufik & 14 & 154 \\
\hline 20 & Ocong & 13 & 146 \\
\hline 21 & Hamdan & 13 & 140 \\
\hline 22 & Fajar & 10 & 130 \\
\hline 23 & jeffrey & 16 & 163 \\
\hline 24 & Taufik & 21 & 153,5 \\
\hline 25 & Ismail & 16 & 139,5 \\
\hline 26 & Sri & 12 & 136 \\
\hline 27 & Aisyah & 7 & 121 \\
\hline 28 & Alisyah & 6 & 109 \\
\hline 29 & Putra & 4 & 104 \\
\hline 30 & Dewi & 28 & 152 \\
\hline 31 & Nurfatia & 1 & 71,5 \\
\hline 32 & Nawas & 6 & 117 \\
\hline 33 & Lisa & 5 & 92,5 \\
\hline 34 & Aditya & 1,1 & 68,5 \\
\hline 35 & Nurazizah & 3,5 & 88 \\
\hline 36 & Ayan & 2 & 84,5 \\
\hline 37 & Mifta & 4 & 105 \\
\hline 38 & Acil & 1,4 & 80 \\
\hline
\end{tabular}

\section{KESIMPULAN DAN SARAN}

Pengetahuan masyarakat bertambah dari tidak tahu sama sekali menjadi tahu dan pada analisa dan hasil pemeriksaan tinggi badan dan usia pada anak panti didapatkan dari 38 peserta, terdapat 8 orang anak yang berusia 0-5 tahun dan 3 orang diantaranya menderita stunting dengan persentase $37,5 \%$ 


\section{DAFTAR PUSTAKA}

1. Margawati A, Astuti AM. Pengetahuan ibu, pola makan dan status gizi pada anak stunting usia 1-5 tahun di Kelurahan Bangetayu, Kecamatan Genuk, Semarang. J Gizi Indones (The Indones J Nutr. 2018;

2. Hadi MI, Kumalasari MLF, Kusumawati E. Faktor Risiko yang Berhubungan dengan Kejadian Stunting di Indonesia: Studi Literatur. J Heal Sci Prev. 2019;3(2):86-93.

3. Lestari EF, Dwihestie LK. ASI Eksklusif Berhubungan dengan Kejadian Stunting pada Balita. J Ilm Permas J Ilm STIKES Kendal. 2020;10(2):129-36.

4. Wati L, Monarisa M, Rikandi M. Pengaruh Berat Badan Lahir Rendah dengan Kejadian Stunting pada Anak Usia 12-23 Bulan di Wilayah Kerja Puskesmas Lubuk Buaya Padang Tahun 2019. J Ilm Univ Batanghari Jambi. 2019;19(3):615.

5. Nadiah S, Wahyu Ningtyias F, Sulistiyani S. Tinggi badan orang tua , pola asuh, dan kejadian diare sebagai faktor risiko kejadian stunting pada balita di Kabupaten Bondowoso toddler in Bondowoso District. Ilmu Gizi Indones. 2020;04(01):11-8.

6. Dyah E. Kejadian Stunting Pada Balita Usia 25-59 Bulan. 2020;9(1):55-60.

7. Apriluana G, Fikawati S. Analisis Faktor-Faktor Risiko terhadap Kejadian Stunting pada Balita (0-59 Bulan) di Negara Berkembang dan Asia Tenggara. Media Penelit dan Pengemb Kesehat. 2018;28(4):247-56.

8. Mediani HS. Predictors of Stunting Among Children Under Five Year of Age in Indonesia: A Scoping Review. Glob J Health Sci. 2020;12(8):83.

9. Supriyanto Y, Paramashanti BA, Astiti D. Berat badan lahir rendah berhubungan dengan kejadian stunting pada anak usia 6-23 bulan. J Gizi dan Diet Indones (Indonesian J Nutr Diet. 2018;5(1):23.

10. Wijayanti A, Djuwita R. The relationship of low birth weight babies with stunting in toddlers aged 12-36 months in bogor regency, 2019. Indian J Public Heal Res Dev. 2020;

11. Sukmawati, Hendrayati, Chaerunnimah, Nurhumaira. Status Gizi Ibu Saat Hamil , Berat Badan Lahir Bayi. Media Gizi Indones. 2018;25:18-24.

12. Ibrahim IA, Bujawati E, Syahrir S, Adha AS. Analisis determinan kejadian Growth failure (Stunting) pada anak balita usia 12-36 bulan di wilayah pegunungan desa Bontongan Kecamatan Baraka Kabupaten Enrekang. Al-Sihah Public Heal Sci J. 2019;11:50-64. 